\title{
Evaluation of the effect of acetazolamide on cystoid macular oedema in patients with Behcet's disease
}

Abstract

Aim To study the effect of acetazolamide on cystoid macular oedema (CMO) in patients with Behcet's disease.

${ }^{1}$ Department of Ophthalmology Tehran Medical Sciences University

Tehran, Iran

${ }^{2}$ Department of

Rheumatology

Tehran Medical Sciences University

Tehran, Iran

${ }^{3}$ Department of Social Medicine

Tehran Medical Sciences

University

Tehran, Iran

${ }^{4}$ Department of Ophthalmology Norfolk and Norwich University Hospital Norwich, UK

\section{Correspondence:}

B Beigi

Department of

Ophthalmology

Norfolk and Norwich

University Hospital Colney

Lane

Norwich NR4 7UZ, UK

Tel: + 441603288372

Fax: + 441603288261

E-mail: bijanbeigi@

ukonline.co.uk

Received: 10 July 2002 Accepted in revised form: 19 November 2002
Patients and methods A total of 67 eyes of 35 Behcet's patients with chronic, but wellcontrolled uveitis, and CMO were randomised into a double-masked, crossover trial comparing the effect of acetazolamide $v s$ placebo. The patients received an initial 4-week course of either $250 \mathrm{mg}$ acetazolamide twice daily (b.i.d.) or placebo, followed by a 4-week washout period. They then received a 4-week course of the reverse study medication. An improvement in visual acuity and fundus fluorescein angiographic findings was assessed.

Results In total, 29 patients (55 eyes) completed the trial and were available for analysis. Of the 29, 16 men and 13 were women. The age range was $13-50$ years (mean 33.6 years). Patients on acetazolamide showed a slightly better improvement of angiographic signs (at least by one grade improvement) over that of placebo (12 vs five eyes). They also had less deterioration of angiographic signs over that of placebo (three $v$ s seven eyes). However, these findings were not statistically significant $(P=0.99)$. Acetazolamide had no statistically significant effect $(P=0.53)$ on the improvement of visual acuity of patients over that of placebo (13 vs eight eyes), nor on the deterioration of visual acuity (three vs 11 eyes).

Conclusion Despite seemingly favourable results, the 4-week course of acetazolamide (250 mg b.i.d.) has no statistically significant effect on the improvement of the visual acuity and the fluorescein angiographic findings in Behcet's patients with CMO.
AR Lashay', A Rahimi', H Chams'1 F Davatchi², F Shahram², ZN Hatmi ${ }^{3}$, H Khalkhali ${ }^{3}$ and B Beigi ${ }^{4}$

Eye (2003) 17, 762-766. doi:10.1038/

sj.eye. 6700464

Keywords: macular oedema; acetazolamide; Behcet's disease; cystoid oedema; cystoid macular oedema

\section{Introduction}

Cystoid macular oedema (CMO) is a major cause of reduction of the visual acuity (VA) in patients with uveitis. ${ }^{1-3}$ Different measures such as nonsteroidal anti-inflammatory drugs, corticosteroids, other immunosuppressive agents, grid laser photocoagulation, and pars plana vitrectomy are proposed for the treatment of CMO. ${ }^{1,2,4,5}$ Although Cox et $a l^{6}$ have reported favourable results after the introduction of acetazolamide for $\mathrm{CMO}$, there has been little evidence on the treatment of CMO in Behcet's disease. Therefore, we conducted a randomised, double-masked, crossover trial of acetazolamide for $\mathrm{CMO}$ in patients with controlled, chronic posterior uveitis.

Patients and methods

During a 42-month period (1996-2000), 35 patients fulfilling the international study group criteria for complete Behcet's disease were enrolled. They had clinically controlled chronic posterior uveitis with minimal vitritis and vasculitis. They were not on any immunosuppressive agents such as steroid. Some remained on nonsteroidal antiinflammatory agents. Other inclusion criteria were a minimum age of 12 years and best corrected visual acuity (BCVA) of 6/7.5 (20/25) or worse in at least one eye. Exclusion criteria 
were receiving acetazolamide as part of the current therapeutic regimen, history of hypersensitivity to acetazolamide, sulphonamides and fluorescein, significant hazy media that obscured fundus fluorescein angiography (FFA), macular ischaemia, and macular lesion including macular hole or scar.

After obtaining informed consent, all patients had baseline ocular examination including measurement of BCVA by Snellen's chart, slit-lamp biomicroscopy, applanation tonometry, and dilated pupil examination by 90-dioptre lens and indirect ophthalmoscopy. They were, then, assigned randomly to receive acetazolamide $250 \mathrm{mg}$ or placebo orally every $12 \mathrm{~h}$ for 4 weeks (course A). Every other patient was enrolled to the same regimen.

A multivitamin tablet was manufactured in the same shape as acetazolamide by Iran-Darma Company and was used as placebo. After completing course A, the patients were examined and then, there was a 4-week washout period where no study medication was administered. At the end of the washout period, the patients were examined again and then received a 4-week course of the opposite study medication that they were assigned in course A (course B). At the end of course $B$, the patients were examined again (12th week examination). Standard FFA was performed at the start of the study and then was repeated at week 4,8 , and 12. Late frames were obtained at $5 \mathrm{~min}$ during each FFA.

Both patients and investigators were masked to randomisation except one ophthalmologist who monitored patients' compliance and drug-adverse reactions. All patients continued their nonsteroidal antiinflammatory medications during the study course and all were recorded at each visit. Fluorescein angiograms were graded, using a modification of a grading system proposed by Miyake ${ }^{7}$ and Fishman et al. ${ }^{8}$

In brief, grading consists of grade $\mathrm{O}$ (no leakage), GIA (trace, murky leakage), GIB (mild leakage not petalloid in appearance nor exceeding $1 / 2$ to $3 / 4$ disc diameter (DD)), GIIA (either partial or complete stellate pattern not exceeding $1 / 2$ to $3 / 4 \mathrm{DD}$ ), GIIB (complete stellate pattern measuring $3 / 4$ but less than $\left.1^{1 / 3} \mathrm{DD}\right)$, GIIIA (complete stellate pattern equal or greater than $1^{1 / 3} \mathrm{DD}$ ) and GIIIB (diffuse leakage throughout the posterior pole beyond $1^{1 / 3} \mathrm{DD}$ ) (Figures $1-3$ ). Transparent templates were used for grading of $\mathrm{CMO}$, and were read by two masked ophthalmologists in random order. Angiograms were studied again for interobserver variations by the same two ophthalmologists. For the third and final time, they studied all the angiograms. This time they were studied in the date order for every patient. One grade change in FFA reading was determined as significant. A masked optometrist under standard conditions checked

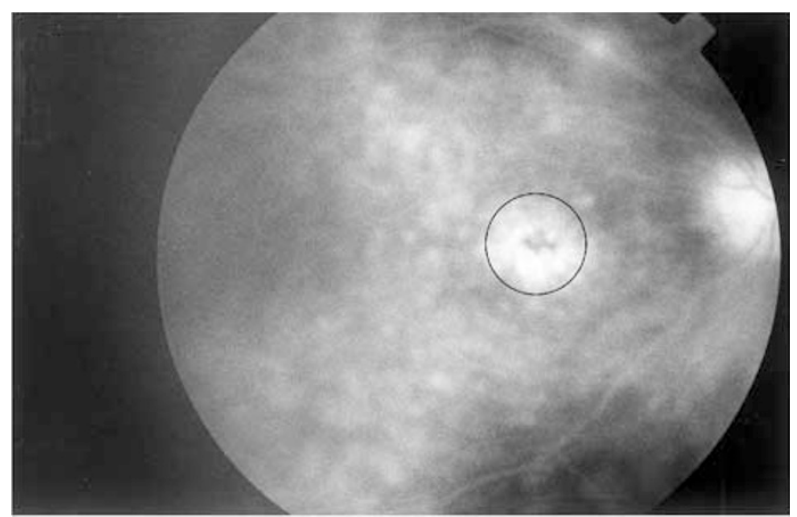

Figure 1 Grade IIIA: complete stellate pattern of fluorescein leakage extending more than $1 \frac{1}{3} \mathrm{DD}$ horizontally.

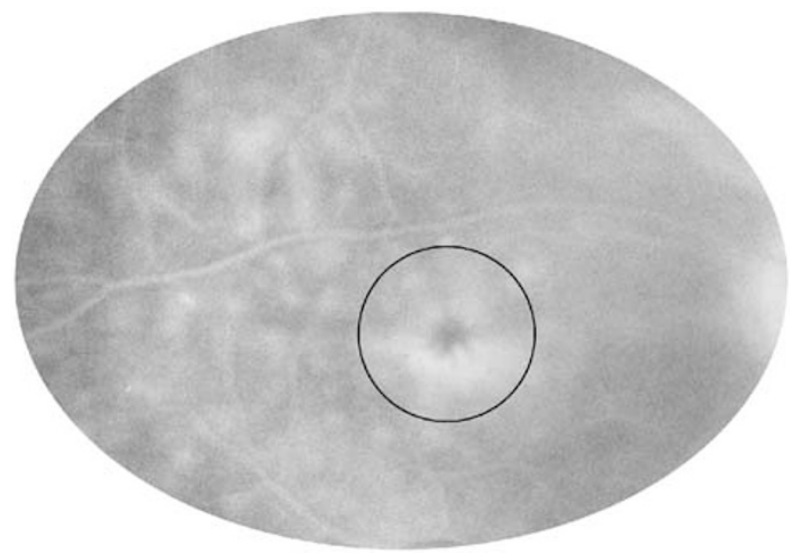

Figure 2 Grade IIB: complete stellate pattern of fluorescein leakage extending from $3 / 4$ to $1 \frac{1}{3} \mathrm{DD}$ horizontally.

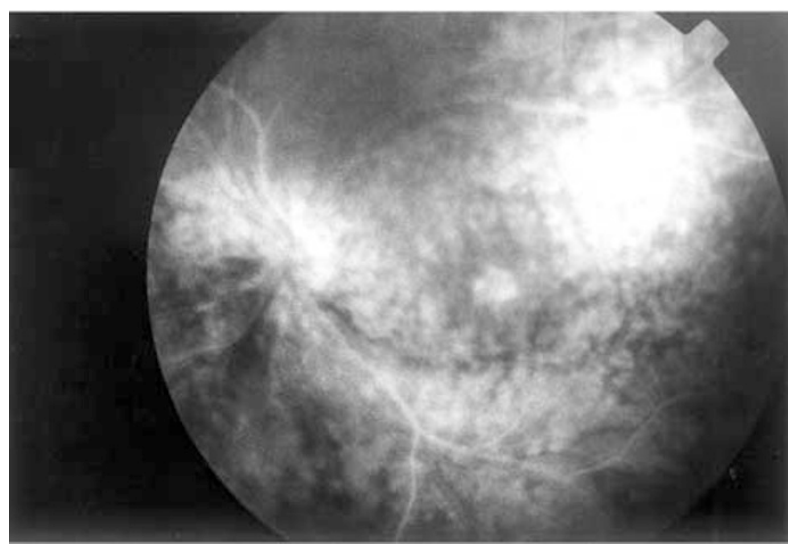

Figure 3 Grade IIB: diffuse fluorescein leakage throughout the posterior pole.

VA. A clinically significant change in VA was defined as a two scale or greater difference in BCVA using Snellen's chart acuity converted to standardised consecutive Log Mar scales. Senn's ${ }^{9}$ approach and SPSS software (spss / win 10.1) were used for statistical analysis. 


\section{Results}

A total of 35 eligible patients were randomised into the study. Of these, 29 patients (55 eyes) completed the trial and were available for analysis; 16 were men and 13 were women. Their mean age was 33.6 years (range 13-50 years). The duration of the disease was 1.5-25 years (mean: 4.6). No important complication, which interrupted the course of acetazolamide, or placebo use, occurred. Few patients reported mild nausea and pins and needles in the extremities but continued with medication. VA changes following the use of acetazolamide and placebo are shown in Table 1. With acetazolamide, VA improved in 13 eyes but deteriorated in three eyes. Overall, 16 patients reported subjective improvement in their VA, while one patient reported subjective deterioration of his acuity. However, in placebo group, eight eyes had an improvement of VA, while 11 eyes had decreased VA. Two patients had subjective improvement in their VA. Independent $t$-test shows no significant effect of acetazolamide on VA of patients $(P=0.53)$, neither on the time effect $(P=0.64)$ nor on the carryover effect $(P=0.45)$.

All patients had minimal vasculitis. FFA changes following the use of acetazolamide and placebo are shown in Table 2. Acetazolamide showed an improvement of $\mathrm{CMO}$ in 12 eyes and worsening of the $\mathrm{CMO}$ in three eyes. In the placebo group, five eyes showed improved $\mathrm{CMO}$, while seven eyes had worsening of the CMO. Independent $t$-test shows no significant effect of acetazolamide on CMO $(P=0.99)$, neither on the time effect $(P=0.42)$ nor on the carryover effect $(P=0.48)$.

In all 13 eyes that had improved vision after acetazolamide, angiographies had either improved (10 eyes) or not changed (three eyes). In all three eyes, in which the VA had deteriorated after acetazolamide, FFAs were unchanged. In eight eyes, in which VA had improved after placebo, FFA was improved in seven, while unchanged in one. In 11 eyes, in which VA had

Table 1 Effect of acetazolamide on VA

\begin{tabular}{lcccc}
\hline & \multicolumn{3}{c}{ Treatment sequence } \\
\cline { 2 - 4 } & Day 1 & Week 4 & Week 8 & Week 12 \\
\hline BCVA & Before placebo & After placebo & Before drug & After drug \\
\cline { 2 - 5 } Range (Log Mar) & 0.430 & 0.430 & 0.537 & 0.448 \\
No. of eyes & $0.1-1.5$ & $0.1-1.5$ & $0.1-1.5$ & $0.1-1.5$ \\
& 27 & 27 & 27 & 27 \\
BCVA & Before drug & After drug & Before placebo & After placebo \\
Range (Log Mar) & 0.632 & 0.604 & 0.596 & 0.626 \\
No. of eyes & $0.1-1.5$ & $0.1-1.5$ & $0.1-1.5$ & $0.1-1.5$ \\
\hline
\end{tabular}

$\mathrm{BCVA}=$ best-corrected visual acuity.

Table 2 Effect of acetazolamide on CMO

\begin{tabular}{lcccc}
\hline & \multicolumn{3}{c}{ Treatment sequence } \\
\cline { 2 - 5 } & Day 1 & Week 4 & Week 8 & Week 12 \\
\hline & Before placebo & After placebo & Before drug & After drug \\
\cline { 2 - 5 } CMO grading & 1.643 & 1.714 & 1.892 & 1.678 \\
Range & $0-4$ & $0-4$ & $0-4$ & $0-4$ \\
No. of eyes & 27 & 27 & 27 & 27 \\
& & & & After placebo \\
CMO grading & Before drug & After drug & 2.5 & 2.535 \\
Range & 2.429 & 2.321 & $1-6$ & $1-6$ \\
No. of eyes & $1-6$ & $0-6$ & 28 & 28 \\
\hline
\end{tabular}

$\mathrm{CMO}=$ cystoid macular oedema. 
worsened after placebo, FFAs were unchanged in eight, deteriorated in two, and improved in one.

Records of six noncompliant patients showed 11 eyes with CMO ranging GIA to GIIB and one eye being GIIB to GIIIA at different intervals. The distribution of signs was the same as the compliant patients.

\section{Discussion}

Cox et $a l^{6}$ and other investigators ${ }^{2,8,10}$ demonstrated that acetazolamide could be of some benefit in reducing the $\mathrm{CMO}$ in uveitis patients. While the exact mechanism by which acetazolamide decreases $\mathrm{CMO}$ remains unclear, several mechanisms of action are proposed. These include regulation of ion transport in the retinal pigment epithelium, ${ }^{2,11}$ inhibition of membrane-bound carbonic anhydrase, ${ }^{12}$ change in chloride flux and the resting potential of the retinal pigment epithelium, ${ }^{13}$ and reduction in subretinal fluid. ${ }^{14}$ However, the clinical effectiveness of acetazolamide in reducing $\mathrm{CMO}$ of patients with uveitis has been controversial. ${ }^{2,15}$ Various factors might alter the final outcomes of acetazolamide therapy for CMO such as severity of vasculitis, macular ischaemia, age of patients, chronicity of $\mathrm{CMO}$, and role of prostaglandin. ${ }^{16,17}$.

To our knowledge, this is the first study on the evaluation of the effect of acetazolamide on $\mathrm{CMO}$ in Behcet's patient. Acetazolamide improved the BCVA and FFA of some of the Behcet's patients. The improvement failed to be statistically significant following the 4-week course of its use.

Our study has been conducted with a fixed dosage of acetazolamide and rather short duration of treatment with acetazolamide. The exact duration of $\mathrm{CMO}$ in our patients was unclear and limited numbers of eligible cases have reduced the power of our study. Some patients continued with their nonsteroidal antiinflammatory treatment. Some patients felt the systemic effect of acetazolamide. These might have compromised the unbiased analysis of the data.

We feel that future studies should address the following issues: detection of the duration of the $\mathrm{CMO}$, trial of various different dosage of acetazolamide with different courses of treatment, selection of more accurate subjective VA measurement charts, ${ }^{18,19}$ and new objective measures for better evaluation and quantification of $\mathrm{CMO}$ such as capillary blood flow velocity measurement, ${ }^{20}$ optical coherence tomography (OCT), ${ }^{21}$ and retinal thickness analyser. These in combination with fluorescein angiography will provide more reliable results. Our study, however, has shown that administration of acetazolamide has little place, if any, in the treatment of Behcet's patients with CMO.

\section{Acknowledgements}

We thank Mrs Khademi for her great help in providing fluorescein angiographic data and Miss D. Rose for her assistance.

\section{References}

1 Smith RE, Godfrey WA, Kimura SJ. Complications of chronic cyclitis. Am J ophthalmol 1976; 82: 277-282.

2 Whitcup SM, Csaky KG, Podgor MJ, Chew EY, Perry CH, Nassenblat A. A randomized, masked, crossover trial of acetazolamide for cystoid macular edema in patients with uveitis. Ophthalmology 1996; 103: 1054-1062.

3 Deane JS, Rosenthal AR. Course and complications of intermediate uveitis. Acta opthalmol scand 1997; 75 (1): 82-84.

4 Suttorp-Schulten MS, Feron E, Postema F, Kijistra A, Rothova A. Macular grid laser photocoagulation in uveitis. Br J Ophthalmol 1995; 79(9): 821-824.

5 Nussenblatt RB. Macular alterations secondary to intraocular inflammatory disease. Opthalmology 1986; 93: 984-988.

6 Cox SN, Hay E, Bird AC. Treatment of chronic macular edema with acetazolamide. Arch Ophthalmol 1988; 166: 1190-1195.

7 Miyake K. Prevention of cystoid macular edema after lens extraction by topical indomethacin, I: a preliminary report. Graefes Arch Clin Exp ophthalmol 1977; 203: 81-88.

8 Fishman GA, Gilbert LD, Fiscell RG, Kimura AE, Jampol LM. Acetazolamide for treatment of chronic macular edema in retinitis pigmentosa. Ophthalmology 1989; 107: 1445-1453.

9 Senn $\mathrm{S}$. The AB/BA crossover, past, present, and future? Stat Methods Med Res 1994; 3: 303-324.

10 Farber MD, Lam S, Tessler HH et al. Reduction of macular oedema by acetazolamide in patients with chronic iridocylitis, a randomized prospective crossover study. $\mathrm{Br} \mathrm{J}$ ophthalmol 1994; 78: 4-7.

11 Moldow B, Sander B, Larsen M, Engler C, Li B, Rosenberg T et al. The effect of acetazolamide on passive and active transport of fluorescein across the blood-retina barrier in retinitis pigmentosa complicated by macular oedema. Graefes Arch Clin Exp Ophthalmol 1998; 236(12): 881-889.

12 Wolfensberger TJ, Dmitriev AV, Govardovskii VI. Inhibition of membrane-bound carbonic anhydrase decreases subretinal pH and volume. Doc Ophthalmol 1999; 97 (3-4): 261-271.

13 Kawasaki K, Mukoh S, Yonemura D, Fujii S, Segawa Y. Acetazolamide-induced changes of the membrane potentials of the retinal pigment epithelial cell. Doc Ophthalmol 1986; 63: 375-381.

14 Marmor MF, Negi A. Pharmacologic modification of subretinal fluid absorption in the rabbit eye. Arch Ophthalmol 1986; 104: 1674-1677.

15 Guex-Crosier Y, Othenin-Girard P, Herbert CP. Acetazolamide may be sufficient for pseudophakic cystoid macular edema (CME) but not for uveitis CME. in : Dernouchamps JP, Verougstraete C, Tassignon MJ (eds). Caspar's velul: Recent Advances in Uveitis. Kugler: Amsterdam, 1993, pp 573-575.

16 Schilling H, Pauleikhoff D, Schreuk M, Wessing A. Therapy of cystoid diffuse macular edema after uveitis and cataract surgery with the carbonic anhydrase inhibitor acetazolamide (Diamox). Klin Monatsbl Augenheild Kd 1993; 202(3): 206-211. 
17 Dick AD. The treatment of chronic uveitic macular oedema is immunosuppression enough? [Editorial]. Br J Ophthalmol 1994; 78: 1-2.

18 Bailey LB, Lovey JE. New design principles for visual acuity letter charts. Am J Optom Physiol Opt 1976; 53: 740.

19 Ferris III FL, Kassoff A, Bresnick GH, Bailey I. New visual acuity charts for clinical research. Am J Ophthalmol 1982; 94: 91-96.
20 Ohnishi Y, Fujisawa K, Ishibashi T, Jojima H. Capillary blood flow velocity measurements in cystoid macular edema with the scanning laser ophthalmoscope. Am J Ophthalmol 1994; 117: 24-29.

21 Hee MR, Puliafito CA, Wong C, Duker JS, Reichel E, Rutledge B et al. Quantitative assessment of macular edema with optical coherence tomography. Arch Ophthalmol 1995; 113: 1019-1029. 